\title{
Magnetic monitoring, geochemical and mineralogical analysis of settled dust from North and Central Transdanubia, Hungary
}

\author{
Emô Márton \\ Paleomagnetic Laboratory, Geological and \\ Geophysical Institute of Hungary, Budapest
}

\author{
Norbert Zajzon \\ Institute of Mineralogy and Geology, \\ University of Miskolc, Miskolc
}

\author{
Péter Sipos \\ Institute for Geological and Geochemical Research, \\ Research Centre for Astronomy and Earth Sciences \\ Hungarian Academy of Sciences, Budapest \\ Tibor Szentmarjay \\ Central Transdanubian Environmental, \\ Nature Conservancy \& Water Policy Inspectorate, \\ Veszprém
}

Mihály Pethe

Geophysics Department, Eötvös Loránd University
Péter Lautner

North Transdanubian Environmental,
Budapest

Ferromagnetic grains in airborne dust are important indicators of vehicle traffic, some industrial sources and combustion/heating. Settled dust consists mainly of diamagnetic material; therefore accessory ferromagnetic grains are readily indicated by magnetic measurements. In this paper settled dust samples collected on a monthly basis in the years 2008-2011 were studied. Non-destructive magnetic measurements were followed by geochemical and mineralogical analyses. In selected samples we identified airborne anthropogenic materials (e.g. silicate and magnetite spherules), minerals from the natural environment and organic material. Seasonally appearing materials (e.g. soot in winter, plant fragments and pollen in summer) increased the mass of the settled dust, but not the magnetic susceptibility. Thus, we realized that the generally interpreted mass susceptibility in environmental magnetic studies would not always appropriately characterize the magnetic pollution. In the interpretation we gave preference to total susceptibility because of its direct connection to the pollution, except in comparison with metal concentrations.

Trends in magnetic pollution were eventually analyzed for 19 sampling sites. Irrespective of the degree and source of the pollution the monthly variation curves of magnetic susceptibility exhibit a general maximum (March-April), followed by gradual decrease. A corresponding peak is observed in the amounts of dust. Both can be explained by re-suspension of dust settled in winter. The additional maxima in the mass of the dust (June and August, respectively) are probably due to contribution from vegetation and/or an artifact from algaecide. For three key sampling sites comparison was made

Addresses: E. Marton: H-1145 Budapest, Columbus utca 17-23, Hungary, e-mail: paleo@mfgi.hu P. Sipos: H-1112 Budapest, Budaörsi út 45, Hungary, e-mail: sipos@geochem.hu N. Zajzon: H-3515 Miskolc, Egyetemváros, Hungary, e-mail: askzn@uni-miskolc.hu T. Szentmarjay: H-8201 Veszprém, Pf. 173, Hungary, e-mail: tibor@szentmarjay.hu P. Lautner: H-9021 Győr, Árpád út 28-32, Hungary, e-mail: lautner@edktvf.kvvm.hu M. Pethe: H-1117 Budapest, Pázmány Péter sétány 1/C, Hungary, e-mail: mifimester@gmail.com

Received: January 21, 2013; accepted: March 26, 2013 
between the concentrations of 12 metals and the respective mass susceptibilities and good linear correlation was found for $\mathrm{Fe}, \mathrm{Mn}$ and $\mathrm{Zn}$ for all, for $\mathrm{Cr}, \mathrm{Cu}, \mathrm{Pb}, \mathrm{V}, \mathrm{Ba}, \mathrm{Sr}$ and $\mathrm{Zr}$ for two sampling sites. $\mathrm{Cd}$, which is enriched in all samples, does not correlate with the magnetic susceptibility.

Key words: Environmental magnetism, Hungarian air monitoring stations, settled dust, composition, total susceptibility, mass susceptibility, long-term susceptibility trends

\section{Introduction}

Before the installation of a network of PM10 air quality monitoring sampling sites, settled dust was collected on a monthly basis at large number of points in Hungary. The sampling sites were operated by different environmental inspectorates, according to the MSZ 21454-1:1983 Hungarian standard. The inspectorates were primarily interested in gaining information about the monthly and geographic distribution of the mass of the settled dust. However, three of the inspectorates, the North Hungarian, the North Transdanubian and the Central Transdanubian handed over the systematically collected samples for scientific investigations to the Paleomagnetic Laboratory of the present Hungarian Geological and Geophysical Institute, where the magnetic susceptibility of all samples from 34 sampling sites (total of 1081 samples) were first measured (Fig. 1). Apart from the total susceptibility of the settled dust, mass susceptibility was also determined. Based on the value of the total magnetic susceptibility, which has a direct relation to anthropogenic sources in most environments, three sampling sites were selected for more detailed studies. These were Sopron (Fig. 1, G9), where the main source of magnetic pollution must be vehicle traffic, Lábatlan (Fig. 1, G6), with a cement and a ferro-concrete factory, and Mosonmagyaróvár (Fig. 1, G7), where vehicle traffic as well as a reservoir of red mud can contribute to air pollution.

From each of these sampling sites, samples collected during 2008 (a total of 36 samples) were studied for their mineralogical and chemical composition. Moreover, special magnetic experiments were carried out on selected samples. The total and mass susceptibilities determined for each month from the key sampling sites as well as from 16 other sampling sites (with three or four years' worth of records of settled dust) were analyzed and compared with the respective masses of the settled dust, followed by a similar analysis of monthly averages for different years. As a next step, an overall average was calculated from the monthly averages for different years for all sampling sites from two inspectorates, since the records of the North Hungarian inspectorate were short and discontinuous. The results of the different laboratory investigations and the analysis of the long-term monitoring of settled dust and its magnetic susceptibility at different sampling sites will be presented in this paper.

Our main goal was to compare monitoring stations from the viewpoint of dust amount and magnetic pollution, identify and compare general trends in the monthly distribution of the amount of settled dust and its magnetic susceptibility. 


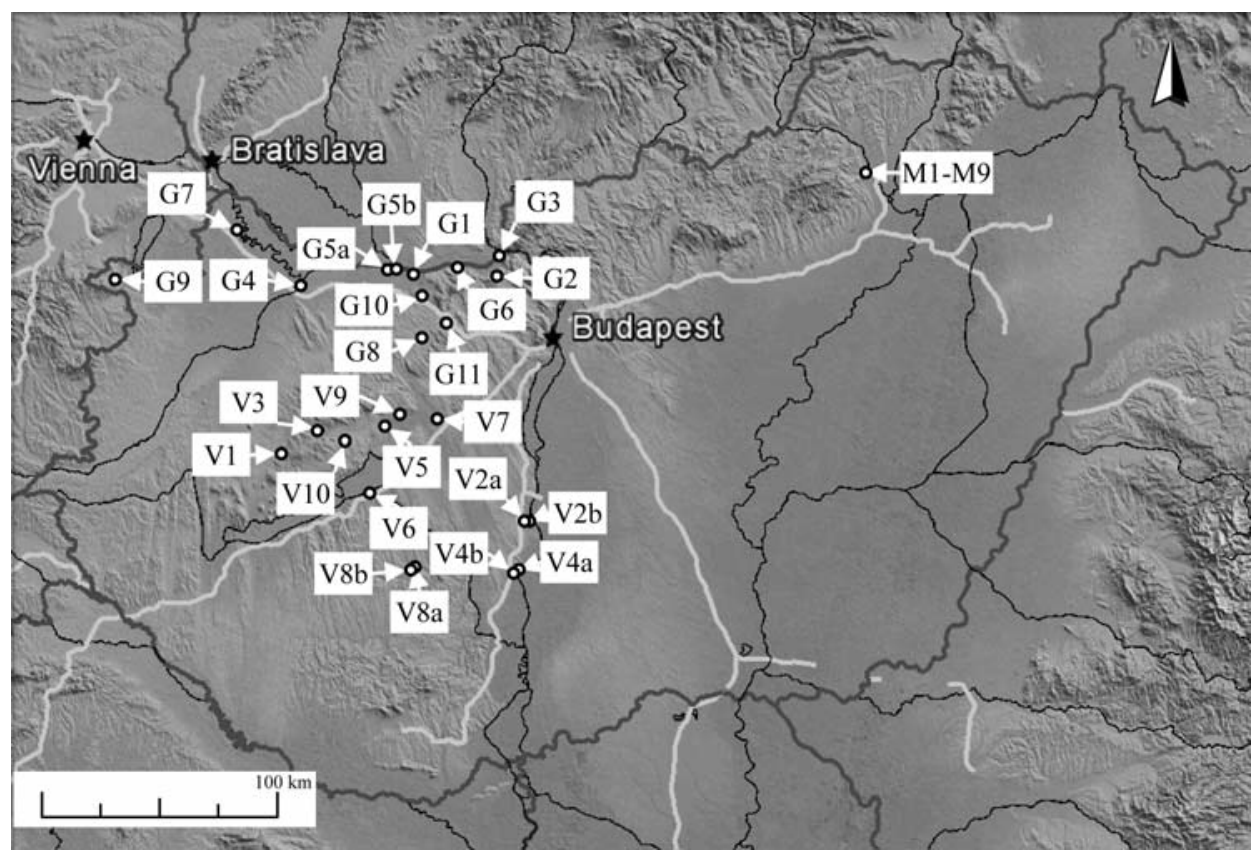

Fig. 1

Collecting sites of settled dust in North (G1-11) and Central (V1-10) Transdanubia and in Miskolc and surroundings (M1-M9). Codes will be used throughout the text. Localities of the 19 sites studied for long-term variations: G1 - Almásfüzitő, G2 - Dorog, G4 - Gyốr, G5a and G5b - Komárom, G6 Lábatlan, G7 - Mosonmagyaróvár, G8 - Oroszlány, G9 - Sopron, G10 - Tata, G11 - Tababánya, V2a Dunaföldvár, Autel, V2b - Dunaföldvár, városháza, V4a - Paks, óvoda, V4b - Paks, tüdőgondozó, V5 - Pétfürdő, V8a - Tamási, Dózsa Gy. u., V8b - Tamási, Hársfa u., V9 - Inota

We also aimed at estimating the contribution of the magnetite in the superparamagnetic (and close to superparamagnetic) grain size range (mostly emitted by vehicles) to the magnetic pollution and supply information about the heavy metals which migrate with the magnetic pollutants and which originate from other sources.

\section{Methods}

\section{Sampling}

Settled dust samples were collected by the different inspectorates according to the MSZ 21454-1:1983 Hungarian standard. This method consists of exposing a $200 \mathrm{~cm}^{2}$ surface area bucket of $1.2-1.5 \mathrm{~m}$ height for one calendar month. The buckets contain $500 \mathrm{ml}$ distilled water $(0.5 \mathrm{~g}$ Nipagin-N was added during summer months as algaecide). The buckets are not covered; therefore they collect bulk deposition. The water containing the settled dust is filtered in the laboratory. 


\section{Magnetic measurements}

Each sample was placed in a small plastic bag and the total susceptibility was measured with a KLY-2 Kappabridge of high sensitivity. The sample holder of the instrument, the filters and the plastic bags are diamagnetic (that is, they have negative susceptibilities). Correction was made for their magnetic contribution to the total susceptibility. The correction comprised the susceptibility of the sample holder, measured before each run of the settled dust measurements, and the average susceptibilities of several filters and of several plastic bags. Such correction is very precise, since the susceptibility of the sample holder may not be sufficiently constant, but there is little variation among filters as well as among the plastic bags. The next step was the calculation of mass susceptibility, using the mass of the sample on the filter supplied by the respective inspectorate.

For each sampling site the total, and separately the mass susceptibilities, were plotted against the year and month they were representing; thus it was possible to analyze the variation of the magnetic pollution with time. From the samples some with high magnetic signal were selected for special magnetic measurements. The experiments included stepwise isothermal remanent magnetization (IRM) of the sample in order to determine if the magnetic mineral was magnetically soft (most likely magnetite) or hard (e.g. hematite), and susceptibility measurements at different frequencies. The latter were made with a MFK1-FA multifunction instrument in Brno (Czech Republic), in order to detect if tiny superparamagnetic grains (smaller than $0.03 \mu \mathrm{m}$ for magnetite) contributed to the magnetic pollution. The advantage of the above-described magnetic methods is that they are non-destructive and do not require the removal of the particles from the filter. Thus, after the magnetic measurements it is possible to proceed with geochemical and/or mineralogical analysis.

\section{Mineralogical and geochemical analyses}

Following the non-destructive magnetic measurements, all samples from three sampling sites (G6, G7 and G9) collected during 2008 were selected for mineralogical and chemical analyses. For the bulk mineralogical analysis, the dust samples were manually separated from the filters and analyzed with a Philips $1710 \mathrm{X}$-ray diffractometer using the following sample preparation: $40 \mathrm{mg}$ of the samples were suspended in ethanol and then deposited onto glass plates with an area of $12 \mathrm{~cm}^{2}$.

Three settled dust filters (samples collected at G9, G6 and G7 in June 2011) were investigated by scanning electron microscope (SEM) combined with energy dispersive X-ray spectrometry (EDX). The analyses were made on a JEOL JXA8600 Superprobe electron microscope, equipped with an E2V Scientific silicon drift detector (SDD). A $15 \mathrm{kV}$ acceleration voltage and $10 \mathrm{nA}$ probe current were used for the investigations. Two sister specimens were prepared from each of the investigated filters, to be able to observe the different size fractions. The larger 
particles were removed from the filter scraping them with a scalpel, and placed onto an adhesive carbon tape. The smaller grains were investigated in situ on the filter after complete removal of larger particles. For the SEM-EDX measurements a conductive carbon coating was applied to all the samples.

For chemical analysis, all filters collected during 2008 at localities G9, G6 and G7 were treated together with the previously removed dust with dry ashing, followed by lithium-metaborate digestion. First, filters with the dust were impregnated with a $50 \% \mathrm{MgNO}_{3}$ solution and dried at $50^{\circ} \mathrm{C}$ to reduce the chance of volatilization of the dust components during the digestion process. Then the impregnated samples were incinerated at $500^{\circ} \mathrm{C}$. The remaining ash was mixed with lithium-metaborate and fused in platinum crucibles. The molten mixtures were poured into nitric acid solution and shaken until dissolved. Concentrations of Fe and further 11 trace elements $(\mathrm{Ba}, \mathrm{Cd}, \mathrm{Cr}, \mathrm{Cu}, \mathrm{Mn}, \mathrm{Ni}, \mathrm{Pb}, \mathrm{Sr}, \mathrm{V}, \mathrm{Zn}$ and $\mathrm{Zr}$ ) in the solutions were analyzed by a Spectro Genesis ICP-OES spectrometer. Table 1 shows the detection limit values for the studied elements.

Geoaccumulation indices $\left(\mathrm{I}_{\text {geo }}\right)$ were also calculated after Ji et al. (2008) using the formula Igeo $=\ln \left(C_{e} / 1.5^{*} B_{e}\right)$, where Ce is the concentration of metal in the sample $(\mathrm{mg} / \mathrm{kg})$ and Be is the geochemical background value $(\mathrm{mg} / \mathrm{kg})$ of the same element. The constant 1.5 allows us to analyze natural fluctuations in the concentration of a given substance in the environment and to detect very small anthropogenic influences. The geoaccumulation index consists of the following simplified classes: $<0$ practically uncontaminated, $0-3$ moderately contaminated, 3-5 heavily contaminated, $>5$ extremely contaminated. As local background values are not available, regional background values were chosen from the geochemical map of Hungary (Ódor et al. 1997) for most of the elements except $V$ and $\mathrm{Zr}$ where average upper crust values were used (Rudnick and Gao 2003). These concentration values are as follows: $24481 \mathrm{mg} / \mathrm{kg}$ for Fe, $774 \mathrm{mg} / \mathrm{kg}$ for Mn, $98 \mathrm{mg} / \mathrm{kg}$ for Ba, $0.65 \mathrm{mg} / \mathrm{kg}$ for Cd, $25 \mathrm{mg} / \mathrm{kg}$ for Cr, $25 \mathrm{mg} / \mathrm{kg}$ for Cu, $22 \mathrm{mg} / \mathrm{kg}$ for $\mathrm{Ni}, 21 \mathrm{mg} / \mathrm{kg}$ for $\mathrm{Pb}, 78 \mathrm{mg} / \mathrm{kg}$ for $\mathrm{Sr}, 97 \mathrm{mg} / \mathrm{kg}$ for $\mathrm{V}, 95 \mathrm{mg} / \mathrm{kg}$ for Zn and 193 $\mathrm{mg} / \mathrm{kg}$ for Zr.

\section{Results and discussion of magnetic, geochemical and mineralogical analyses}

Evaluation of the magnetic susceptibility measurements carried out on the settled dust samples collected during 2008 revealed a strange feature. There was an expressed minimum in the mass susceptibility for August at all sampling sites, which had no explanation in meteorological or other conditions. That is why the mineralogical composition of all samples from Sopron, Lábatlan and Mosonmagyaróvár were analyzed by XRD. We have found that in the settled dust the main components reflecting the geologic environments are in the order of frequency: quartz (generally $>50 \mathrm{wt} . \%)$, feldspar $(<20 \mathrm{wt} . \%)$, dolomite $(<20$ wt. $\%)$, mica $(<5 \mathrm{wt} . \%)$ and chlorite $(<5 \mathrm{wt} . \%)$. Calcite $(<20 \mathrm{wt} . \%)$ also appears in some samples from each site with highest frequency at Lábatlan, followed by 


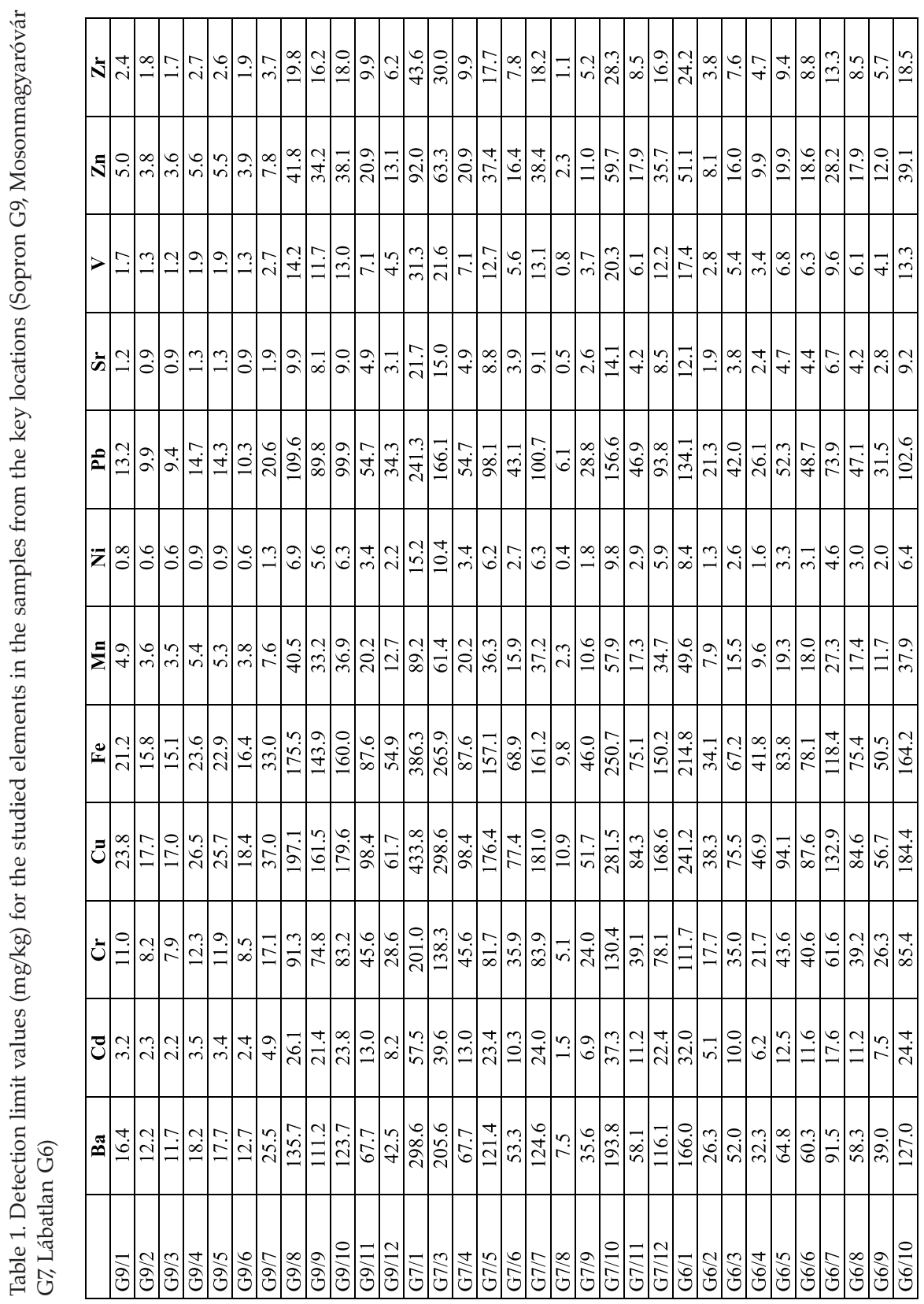




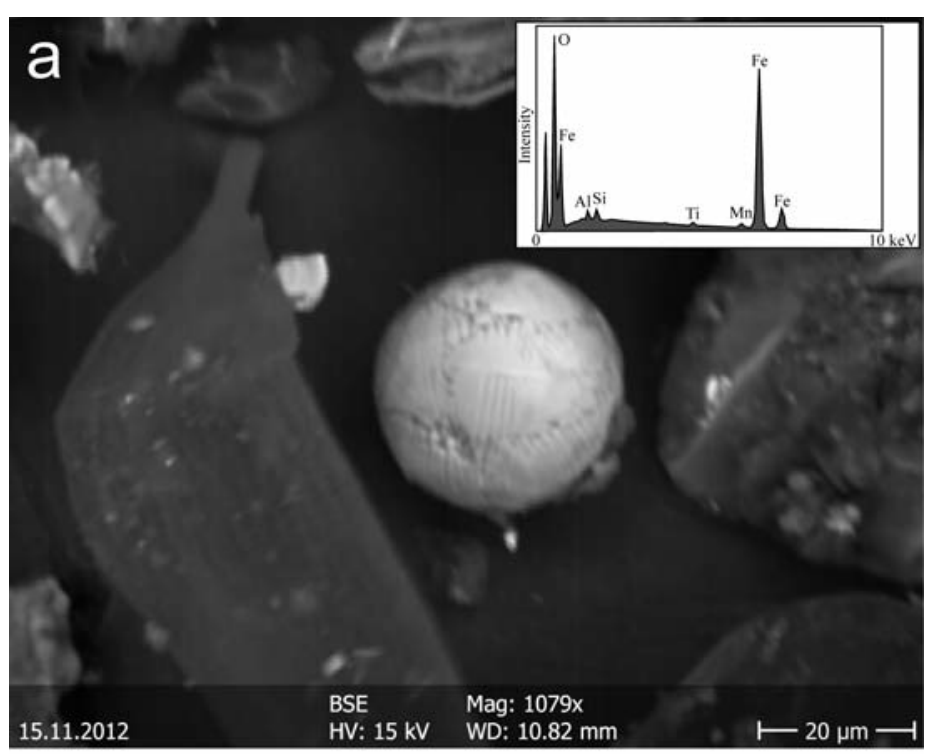

Fig. 2

Backscattered electron (BSE) images of individual spherules from Lábatlan (G6) and their EDX spectra. a: Iron oxide spherule (bright sphere in the center) with minor amount of $\mathrm{Mn}$ and Ti. b: $\quad$ Silicate melt spherule (bright sphere in the center)

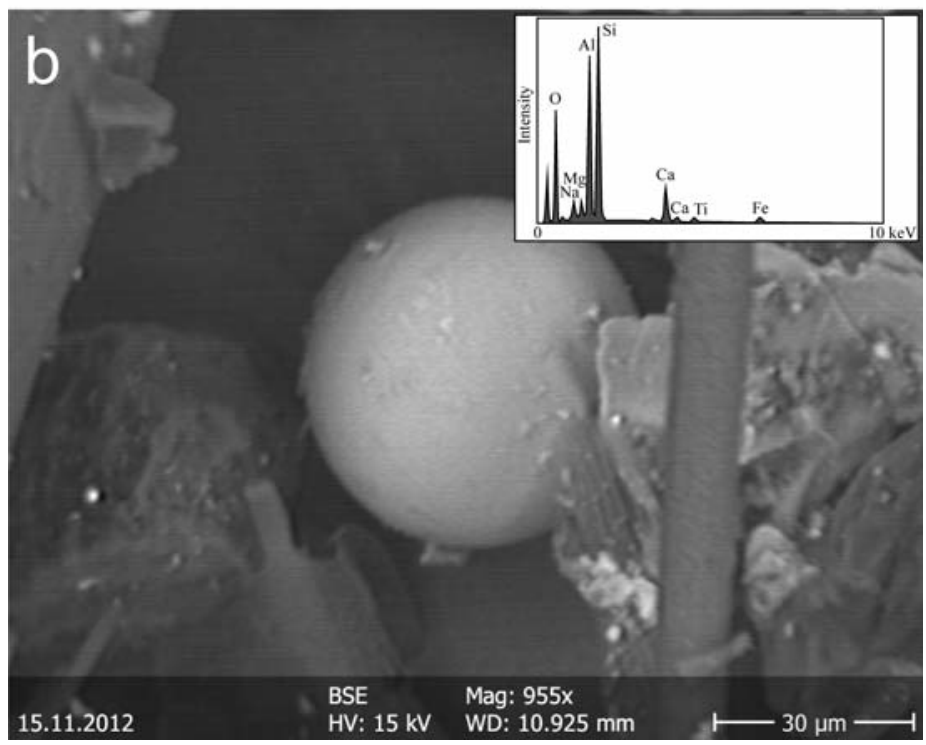

Sopron and Mosonmagyaróvár. Swelling clay minerals $(<5$ wt.\%) are only present in some of the samples from Sopron and in a single sample from Lábatlan. These phases are all characteristic natural components of settled dusts (Farkas and Weiszburg 2006). However, Zhao et al. (2010) found that some portion of silicates and carbonates could also appear in poorly crystallized form in urban settled dust, suggesting an anthropogenic origin. We did identify such materials in the form of silicate spherules at each sampling site (Fig. $2 b$ ). In addition to the 
above phases, amorphous (probably organic) material was also present in the samples, generally below $5 \mathrm{wt} . \%$, but in certain samples from Lábatlan (site G6) their concentration was as high as $20 \mathrm{wt} . \%$. SEM analysis also showed the presence of a large amount of organic material in the samples, such as pollen, plant debris, etc. (Fig. 3). In some samples from site G9 organic material appears partly in crystallized form, as shown by a characteristic X-ray peak at $2.85 \AA$. Apart from the above components, the samples collected in August at all sampling sites contain a large amount (around $50 \mathrm{wt} . \%$ ) of algaecide, which can be due to the evaporation of the water solution from the sampling pots. This finding explains the irrationally low values of the mass susceptibility in August. The presence of the algaecide, the changing amount of organic material and the varying amount of non-magnetic natural minerals all call attention to the risk involved in the mechanical use of either the mass of the "dust" or mass susceptibility in characterizing the degree of air pollution.

Fig. 3

Backscattered electron (BSE) images of settled dust from different locations. a: abundant hairy-spiky pollen particles (dark spheres) in the settled dust from Mosonmagyaróvár (G7). b: different organic fragments (mainly plant and some insect fragments) predominate in a sample from Lábatlan (G6)
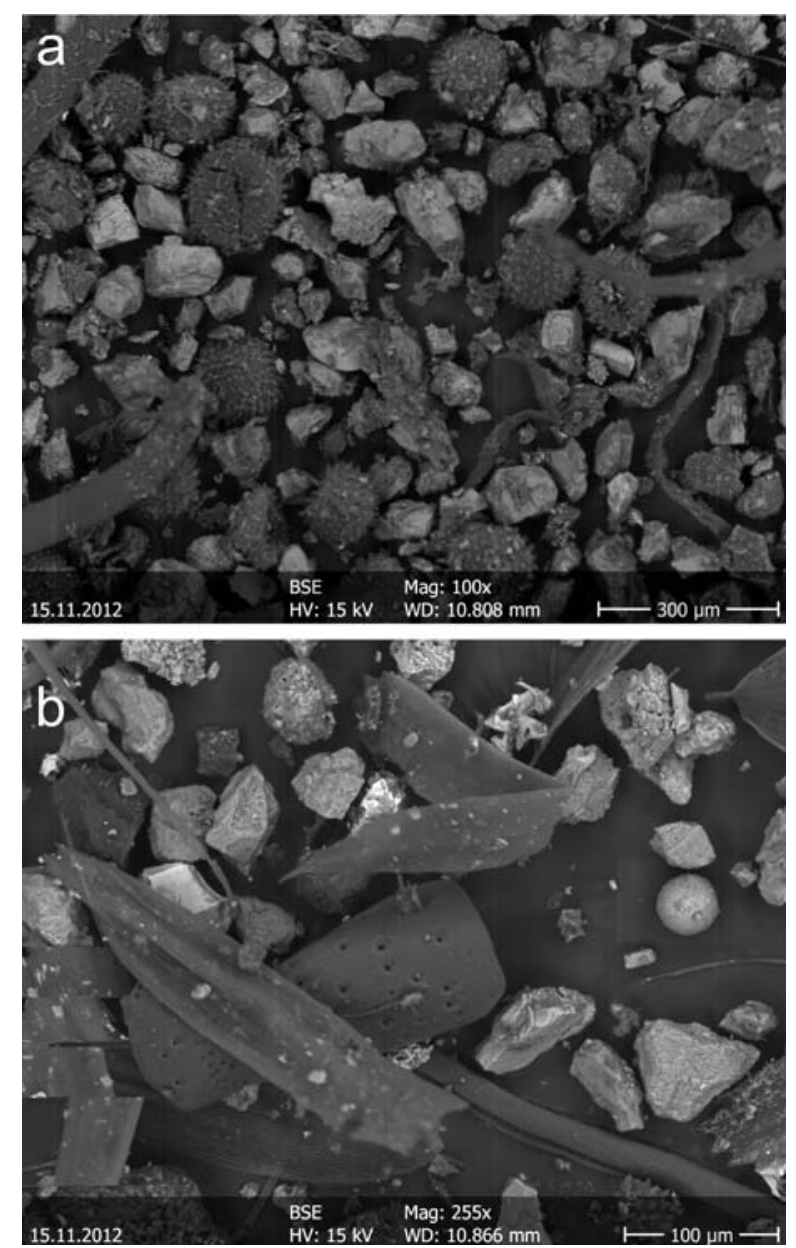
The source of the magnetic susceptibility is thought to be mostly the presence of magnetite spherules of anthropogenic origin. Such spherules are common constituents of airborne particulate matter in the urban environment and they may originate from combustion/heating, traffic and several industrial sources (Zajzon et al. 2013). With the XRD method, trace amounts of spinel-structure phases (probably magnetite) were found in some samples from Sopron and Mosonmagyaróvár. The SEM method identified iron oxide spherules in some studied samples (Fig. 2a). Special magnetic experiments confirm the presence of magnetite in the samples (Fig. 4), which must be of larger grain sizes in the Lábatlan dust than in the other two samples, as the frequency dependence of the magnetic susceptibility is below or close to $2 \%$ in the first and goes up to $8 \%$ in the two latter, which reflect an admixture of superparamagnetic $(<30 \mathrm{~nm})$ and coarser, non-superparamagnetic grains (Dearing 1999). Concentrations of Fe and further 11 trace elements were analyzed in the samples of the year 2008 from the three key sampling sites (Table 2), where we found that their concentrations in these samples were slightly lower than those found in settled dust in Budapest (Márton et al. 2011) or in other Central European towns (e.g. Krolak 2000). Compared to the natural geochemical background (Fig. 5), the analyzed samples are practically uncontaminated by $\mathrm{Fe}, \mathrm{Ba}, \mathrm{Mn}, \mathrm{Sr}, \mathrm{V}$ and $\mathrm{Zr}$. Of the metals which are supposed to be mostly of anthropogenic origin, $\mathrm{Cd}$ shows anomalously high concentration in each studied sample, higher in the Mosonmagyaróvár (G7) and Lábatlan (G6) than in the Sopron (G9) samples, and moderate values were found for $\mathrm{Cr}, \mathrm{Cu}, \mathrm{Ni}, \mathrm{Pb}$ and $\mathrm{Zn}$ (Fig. 5). Cluster analysis based on the linear correlation between the metal concentrations revealed that the Sopron and Lábatlan samples show uniform geochemical characteristics within the respective sampling site,
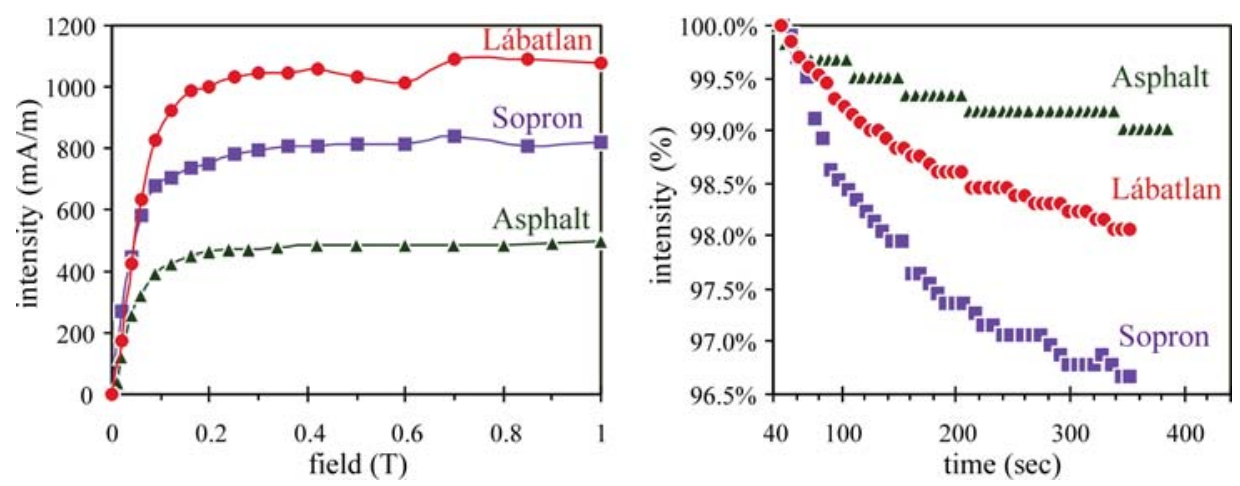

Fig. 4

Isothermal remanence acquisition curves (left side) for Lábatlan (upper curve), Sopron (middle curve) and for asphalt fragments (lower curve) documenting rapid saturation of the remanence, characteristic for soft magnetic minerals such as magnetite or maghemite. On the right side the decrease of the IRM with time is plotted. The upper curve for asphalt and the middle curve for Lábatlan suggest the practical absence of magnetite in or close to the superparamagnetic range, while tiny magnetite grains are present in significant amount in the sample from Sopron 
356 E. Márton et al.

\begin{tabular}{|c|c|c|c|c|c|c|c|c|c|c|c|c|}
\hline$\dot{N}$ & $\approx$ & $\begin{array}{l}\text { đ̃ } \\
0\end{array}$ & 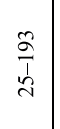 & 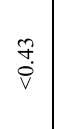 & f & $\begin{array}{l}0 \\
0 \\
0\end{array}$ & $\frac{\partial}{\vec{v}}$ & $\begin{array}{l}\overrightarrow{0} \\
0 \\
0 \\
0\end{array}$ & $\bar{m}$ & $\stackrel{\circ}{\circ}$ & $\frac{\bar{p}}{\frac{1}{6}}$ & 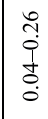 \\
\hline ง & $\stackrel{\infty}{\sim}$ & $\stackrel{3}{3}$ & 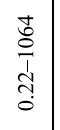 & $\begin{array}{l}n \\
n \\
0 \\
0 \\
0 \\
0\end{array}$ & i̊ & $\stackrel{\Xi}{-}$ & 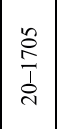 & $\begin{array}{l}n \\
i \\
0 \\
0 \\
0\end{array}$ & $\vec{\sigma}$ & $\stackrel{\infty}{-}$ & 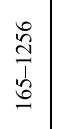 & $\frac{0}{\tilde{j}}$ \\
\hline$>$ & 足 & $\stackrel{7}{0}$ & $\begin{array}{l}\frac{7}{7} \\
\frac{1}{\infty}\end{array} \mid$ & $\begin{array}{c}\tilde{v} \\
\hat{v}\end{array}$ & $\pi$ & $\begin{array}{l}n \\
\dot{0} \\
0\end{array}$ & $\vec{\nabla}$ & 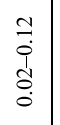 & $\stackrel{\infty}{\curvearrowright}$ & 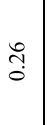 & \begin{tabular}{l}
$\infty$ \\
$\stackrel{\infty}{0}$ \\
$\stackrel{1}{\gamma}$ \\
\multirow{\gamma}{*}{}
\end{tabular} & \begin{tabular}{|l}
$\infty$ \\
0 \\
0 \\
0 \\
0 \\
\end{tabular} \\
\hline$\check{n}$ & $\cong$ & $\begin{array}{l}\hat{s} \\
\hat{o}\end{array}$ & $\begin{array}{l}\vec{F} \\
0 \\
0 \\
0\end{array}$ & $\begin{array}{l}\vec{i} \\
\overrightarrow{0} \\
0\end{array}$ & in & $\because$ & \begin{tabular}{|l|}
0 \\
$\bar{d}$ \\
$d$ \\
$d$
\end{tabular} & $\begin{array}{l}\stackrel{9}{0} \\
0 \\
0 \\
0 \\
0\end{array}$ & 5 & તి & $\overrightarrow{\vec{T}}$ & 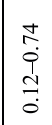 \\
\hline$\stackrel{\Omega}{\AA}$ & $\cong$ & $\begin{array}{l}\hat{n} \\
0\end{array}$ & $\begin{array}{l}\text { ồ } \\
\text { d̦ }\end{array}$ & $\begin{array}{c}\hat{b} \\
\vec{v}\end{array}$ & $\overrightarrow{5}$ & $\begin{array}{l}\text { đે } \\
0\end{array}$ & $\begin{array}{l}\tilde{\tilde{V}} \\
\hat{v}\end{array}$ & $\begin{array}{l}\tilde{B} \\
\dot{\theta}\end{array}$ & F & $\bar{z}$ & $\begin{array}{l}\hat{0} \\
0 \\
0\end{array}$ & 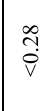 \\
\hline$\overline{\mathbf{z}}$ & \& & $\overrightarrow{0}$ & $\begin{array}{l}\mathbf{d} \\
\stackrel{1}{d} \\
=\end{array}$ & $\begin{array}{c}\text { ते } \\
\stackrel{\nabla}{\nabla}\end{array}$ & $\mathscr{8}$ & $\stackrel{ \pm}{0}$ & $\frac{\infty}{\vec{v}}$ & $\begin{array}{l}\text { స్ } \\
0 \\
0 \\
0 \\
0\end{array}$ & $\stackrel{8}{q}$ & fี & 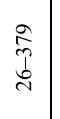 & 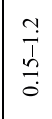 \\
\hline$z$ & $\stackrel{\overbrace{}}{\simeq}$ & $\begin{array}{l}n \\
0 \\
0\end{array}$ & 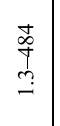 & $\begin{array}{l}\vec{j} \\
\bar{d} \\
0 \\
0\end{array}$ & $\stackrel{\square}{\square}$ & $\stackrel{3}{3}$ & 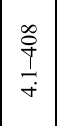 & $\begin{array}{l}0 \\
\hat{0} \\
0 \\
m \\
0\end{array}$ & $n$ & ત્ર & $\begin{array}{l}\stackrel{\infty}{ \pm} \\
\pm \\
\pm\end{array}$ & \begin{tabular}{|l}
$\overline{1}$ \\
0 \\
0 \\
0
\end{tabular} \\
\hline む & I & $\stackrel{\tilde{O}}{\sigma}$ & $\begin{array}{l}\tilde{O} \\
\vec{j} \\
\dot{-}\end{array}$ & $\begin{array}{l}n \\
0 \\
0 \\
0 \\
0 \\
0\end{array}$ & 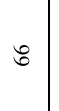 & $\frac{\pi}{0}$ & 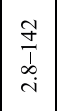 & $\begin{array}{l}\text { त̂ } \\
0 \\
0 \\
0 \\
0\end{array}$ & F & 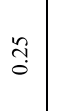 & 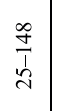 & $\begin{array}{l}0 \\
0 \\
0 \\
0 \\
0 \\
0\end{array}$ \\
\hline 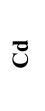 & $\hat{\lambda}$ & $\overrightarrow{0}$ & $\begin{array}{l}\hat{a} \\
\hat{a} \\
-1\end{array}$ & $\begin{array}{l}\hat{\vec{V}} \\
\vec{\nabla}\end{array}$ & $\ddot{\infty}$ & $\frac{7}{0}$ & $\mid \begin{array}{l}\hat{q} \\
\mathrm{v}\end{array}$ & $\begin{array}{l}f \\
f \\
0 \\
0 \\
0 \\
0\end{array}$ & 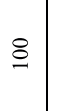 & $\bar{m}$ & $\begin{array}{l}\hat{o} \\
\dot{J} \\
\dot{f}\end{array}$ & 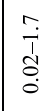 \\
\hline 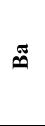 & $\vec{a}$ & $\exists$ & $\begin{array}{l}\infty \\
\infty \\
0 \\
0 \\
n\end{array}$ & $\stackrel{\stackrel{\leftrightarrow}{\mathrm{V}}}{ }$ & 芩 & 声 & 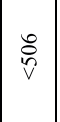 & $\begin{array}{l}0 \\
0 \\
0 \\
0 \\
0 \\
0\end{array}$ & $\mathbb{I}$ & के & $\begin{array}{l}\stackrel{\circ}{d} \\
\stackrel{J}{J}\end{array}$ & $\mid \begin{array}{l}0 \\
0 \\
0 \\
0 \\
0 \\
0 \\
0\end{array}$ \\
\hline$\Sigma$ & $\stackrel{\text { In }}{\mathrm{I}}$ & $\exists$ & 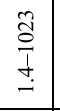 & 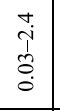 & $\Xi$ & $\stackrel{n}{o}$ & $\underset{\vec{v}}{\stackrel{\sim}{v}}$ & $\begin{array}{l}n \\
0 \\
\infty \\
0 \\
0 \\
\end{array}$ & $\stackrel{\infty}{m}$ & $\Xi$ & $\begin{array}{l}\tilde{n} \\
0 \\
0 \\
\hat{m} \\
-\end{array}$ & $\begin{array}{l}\vec{i} \\
\hat{n} \\
\hat{\sigma} \\
\dot{0}\end{array}$ \\
\hline 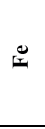 & \begin{tabular}{l} 
चे \\
\multirow{a}{q}{}
\end{tabular} & $\delta$ & 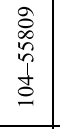 & 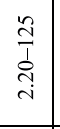 & 悉 & $\stackrel{J}{d}$ & 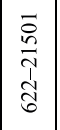 & $\begin{array}{l}\tilde{y} \\
\text { 工े } \\
\end{array}$ & $\begin{array}{l}\text { ¿े } \\
\text { ते }\end{array}$ & $\approx$ & 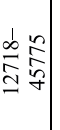 & 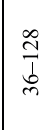 \\
\hline & $\begin{array}{l}\text { 点 } \\
\text { 总 }\end{array}$ & 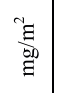 & $\begin{array}{l}\stackrel{\text { Do }}{\mathrm{m}} \\
\stackrel{\mathrm{m}}{E}\end{array}$ & $\begin{array}{l}z \\
z \\
z \\
E\end{array}$ & 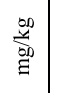 & $\mid \begin{array}{l}z \\
z \\
g \\
g\end{array}$ & 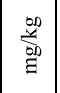 & $\begin{array}{l}z \\
z \\
g \\
g\end{array}$ & 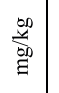 & 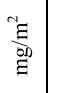 & 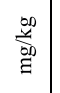 & 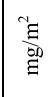 \\
\hline & 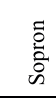 & 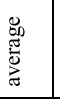 & 흄 & & & & 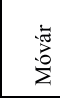 & & 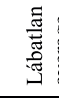 & & 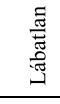 & 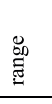 \\
\hline
\end{tabular}

Central European Geology 55, 2012 


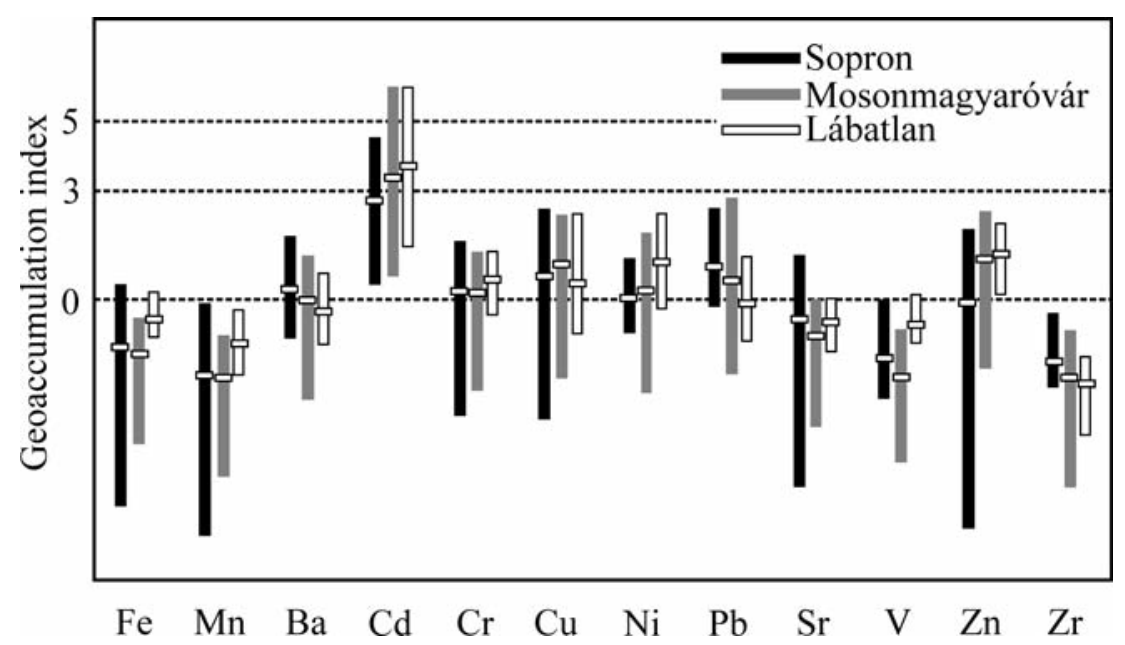

Fig. 5

Geoaccumulation indices were calculated for each metal, as background metal concentrations for settled dust are not available. Their averages (bars) and ranges (columns) are shown on the figure. These values allow us to compare the metal concentrations in the dust to that of surface geologic formations representing the regional geochemical background. Based on the geoaccumulation index, the following sample categories are distinguished: $<0$ practically uncontaminated, $0-3$ moderately contaminated, 3-5 heavily contaminated, $>5$ extremely contaminated

while the samples from Mosonmagyaróvár are more heterogeneous. This latter observation may suggest the higher heterogeneity of potential dust sources in Mosonmagyaróvár.

The relationship between metal concentrations and mass susceptibility was investigated by means of correlation coefficients. We found a strong linear correlation between mass susceptibility and $\mathrm{Fe}, \mathrm{Mn}$ and $\mathrm{Zn}$ concentrations $(r>0.70)$ at each key sampling site. Additionally, most of the other studied metals show a similarly close relationship with mass susceptibility at Sopron (except $\mathrm{Cd}$ and $\mathrm{Pb}$ ) and Mosonmagyaróvár (except $\mathrm{Cd}, \mathrm{Ni}$ and $\mathrm{V}$ ), while this is only true for $\mathrm{Pb}$ and $\mathrm{V}$ in Lábatlan. It is remarkable that $\mathrm{Cd}$, which shows anomalously high concentrations everywhere, does not show a linear relationship with the mass susceptibility.

As the metal concentration is greatly affected by different components appearing seasonally (algaecide, plant-derived materials), monthly metal deposition rates were also calculated (Table 2). Their maximum concentrations are only slightly higher than those found in Hungarian rural areas (Mészáros et al. 1993), but much lower than found by Márton et al. (2011) in Budapest. Some differences are observed among the three study sites: $\mathrm{Ba}, \mathrm{Cr}, \mathrm{Cu}$ and $\mathrm{Pb}$ shows the highest deposition values in Sopron, and $\mathrm{Cd}, \mathrm{V}$ and $\mathrm{Zn}$ in Lábatlan. Mosonmagyaróvár is characterized by the lowest metal deposition values. Similarly to other studies (e.g. Odabasi et al. 2002), we have not found any characteristic monthly or seasonal metal deposition trend. 


\section{Results and interpretation of the magnetic observations}

Starting in 2008, we have obtained samples containing the monthly collected settled dust at more than 30 sampling sites run by the inspectorates mentioned in the introduction. From these sampling sites we measured the magnetic susceptibility of a total of 1081 samples. As the monitoring of the mass of settled dust became a voluntary activity for the inspectorates, they gradually reduced the number of sampling sites and finally abandoned all of them by the end of 2011. For this reason, some records of the monthly variation of the magnetic susceptibility are of short duration and will not be included in the general interpretation. Eventually, the results of magnetic susceptibility monitoring from 19 sampling sites will be evaluated from the viewpoint of general trends in the local and temporal variations of the total and mass susceptibility.

The Lábatlan (G6) and Sopron (G9) sites are characterized by far the highest degree of magnetic pollution. Average total susceptibility for the Lábatlan samples is $44 \times 10^{-6} \mathrm{SI}$ and for the Sopron samples $35 \times 10^{-6} \mathrm{SI}$. In the first case, industry, in the second heavy vehicle traffic, can account for the emission of magnetic grains. At the other sampling sites, the total magnetic susceptibility does not exceed $17 \times 10^{-6}$ SI. When average total susceptibilities are plotted against the respective average mass of dust, poor correlation is obvious (Fig. 6). The explanation is partly the above-discussed problem with the composition of the dust (presence of the algaecide, plant fragments, pollen, etc.), partly the different types of the pollution

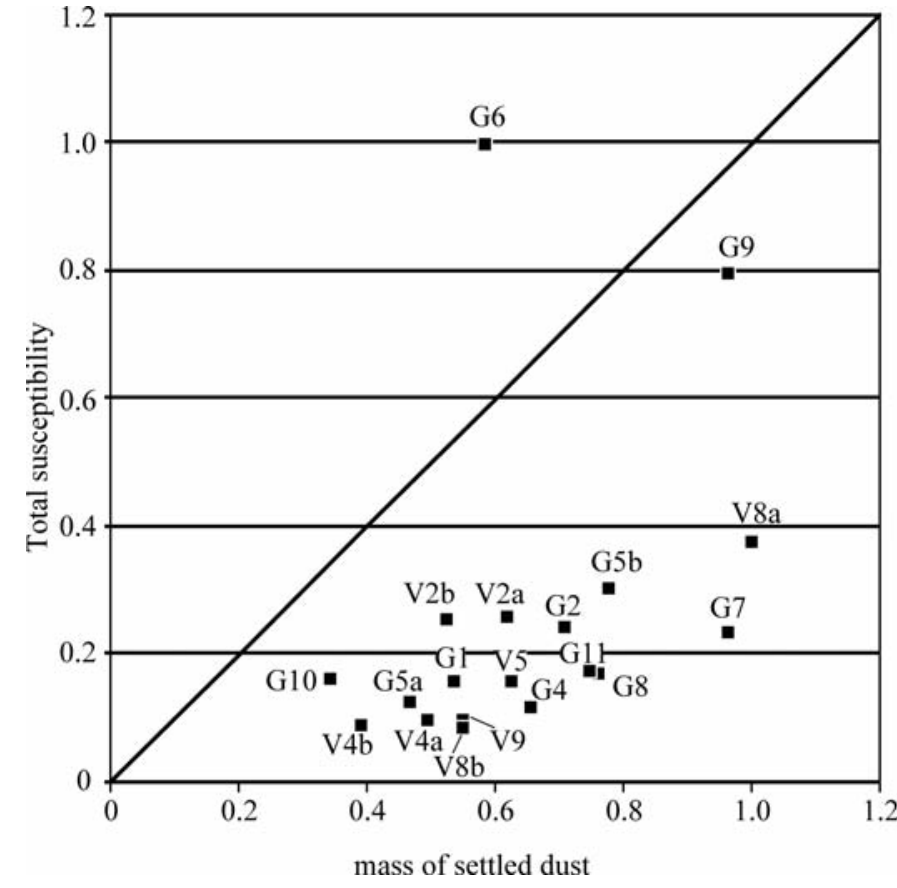

Fig. 6

Correlation between the mass of the settled dust and the total magnetic susceptibility. Both are overall averages (all data from the respective sampling site) and normalized to the maximum overall average, which occurred at sites V8a and G6 for dust mass and total susceptibility, respectively 
sources at different sampling sites. In Lábatlan, the dominance of the industrial sources is obvious; in Sopron the sampling site was located in Csatkai Street, directly affected by heavy vehicle traffic. In the majority of the other sampling sites, the pollution can be attributed to a combination of vehicle traffic and heating. These sampling sites are characterized by a relatively high mass of the dust, while the total susceptibilities are more or less independent of the mass (Fig. 6). The general trends in the temporal variations of the total susceptibility were analyzed at different levels: first the records of one year, than the average of four years for the same sampling site and finally the average of four years for all sampling sites exhibiting common trends and belonging to the same inspectorate were computed. There are some variations between the yearly records of the total susceptibility for the same sampling site, especially when a local and temporally variable source of magnetic pollution is suspected (Fig. 7). When the average susceptibilities for the same sampling site are computed, such occasionally and locally occurring extreme values are excluded.

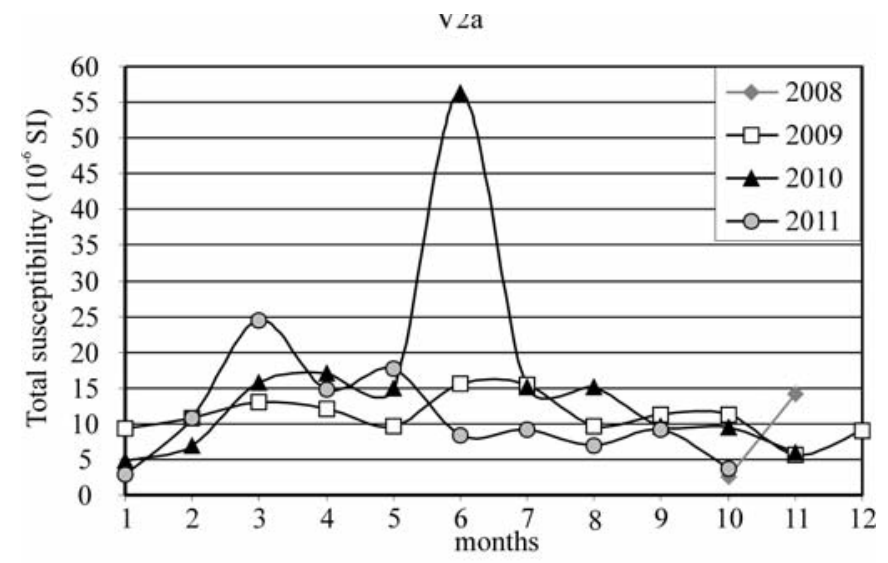

Fig. 7

Monthly variation of the total susceptibility for the period 2008-2011 for two sampling sites in Dunaföldvár (V2a, V2b). Note that extremely high values were measured for both sampling sites in June 2010, when a traffic circle was constructed in Dunaföldvár

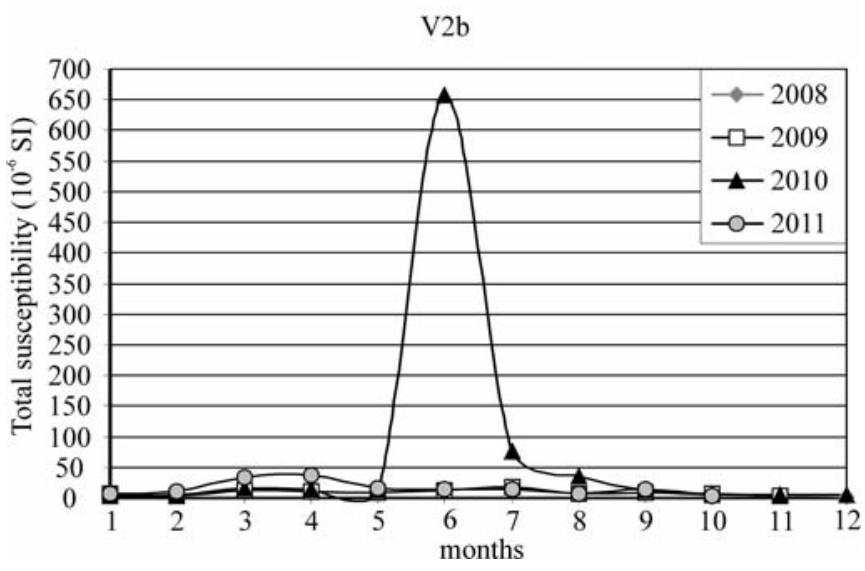


The monthly variations of the 4-year average susceptibilities are likely to reflect the deposition of the anthropogenic magnetic grains coming from more or less stable sources emitting the pollutants and independent of short-term meteorological and other conditions. The average susceptibility curves computed for the different sampling sites have common features, i.e. the monthly variation in the deposition of the magnetic material seems to be basically independent of the location of the collecting site and the source of pollution. On the other hand, the total susceptibility of the dust is definitely much higher in March or April than in January or February; the susceptibility drops in May and it shows a gradual, but not monotonous decrease during the rest of the year (Fig. 8a). The trend in the mass of the settled dust is similar to that of the total susceptibilities for the first five months of the year, suggesting a common source of the ferromagnetic and non-ferromagnetic material. The mass of the settled dust, however, exhibits even higher peaks in June and in August than in April (Fig. 8b). The maxima in the settled dust accumulation after May can be the consequences of periodic accumulation of organic fragments (pollen, etc.), which have no connection with pollution sources emitting magnetic material. It is interesting to note that between May and September, the mass susceptibilities and the mass of the dust exhibit opposing trends, which suggests that the variations are due to the changing amount of non-magnetic components of the dust (Fig. 8c). It is more difficult, however, to account for the maximum in the susceptibility curves and the first peak in the mass of the settled dust.

It is well known that Saharan dust appears in the air from time to time, not only in southern Europe (Sagnotti et al. 2006) or in the Canary islands (Lázaro et al. 2008), but also in Hungary (Borbély-Kiss et al. 2004). It was detected in PM20 and PM10 samples, particularly frequently in March and in November at the Hungarian station of Debrecen. Although, the grain size of the Saharan dust is small, it is not impossible that in favorable circumstances it settles and can thus contribute to the mass of the settled dust. However, the Saharan dust is known for extremely low magnetic susceptibility (Sagnotti et al. 2006; Lázaro et al. 2008); thus it cannot account for the March-April maximum in both the mass and in the total susceptibility.

Another factor to be considered is the breaking up the asphalt during winter, since it contains basalt fragments with strongly magnetic minerals. Indeed the mass susceptibility or the asphalt fragments suggests that their disintegrated

Fig. $8 \rightarrow$

General tends in the monthly variation of total magnetic susceptibility (8a), mass of the settled dust (8b) and of mass susceptibility (8c). Each curve is computed from all data from several collecting sites, which are normalized to the overall average of the magnetic susceptibility (Fig. 8a) to the overall average of the mass of the settled dust (Fig. $8 b$ ) and to the overall value of the mass susceptibility (Fig. 8c) 
Magnetic monitoring, geochemical and mineralogical analysis of settled dust from Hungary 361
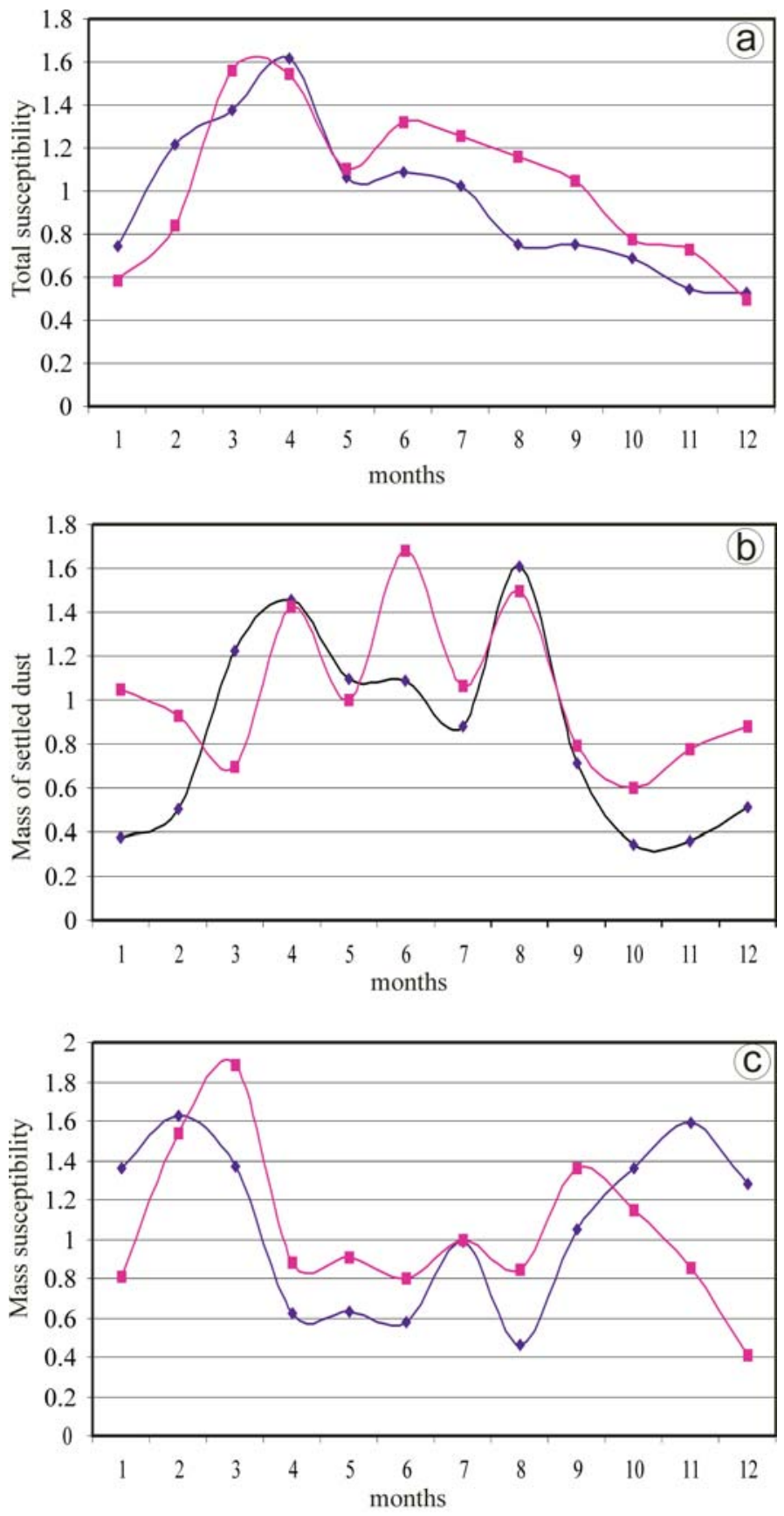

$\rightarrow$ Györ $11 \rightarrow-$ Veszprém 8

Central European Geology 55, 2012 
material must contribute to the ferromagnetic particles of the settled dust. However, both the two-frequency susceptibility measurements and the decay of the IRM with time (Fig. 4) document that ferromagnetic grains in or close to the superparamagnetic range are absent. Thus their presence in the settled dust at most localities calls for an additional source of magnetic material.

Fine particles (less than $0.1 \mu \mathrm{m}$ ) easily transform into larger ones by coagulation, primarily when the humidity of the air gets closer to saturation. In contrast, when ambient relative humidity decreases, condensed water will evaporate, preventing the formation of aggregates (Rood et al. 1987). Particles in the size range between $0.1-1 \mu \mathrm{m}$ have the longest residence time in the air because they neither settle fast nor coagulate (Jaenicke 1984). According to Hayakawa (1964) the coagulation process starts above 55\% relative humidity, and the ratio of the coarse particles $(>1 \mu \mathrm{m})$ continuously increases with the relative humidity of the air (Parameswaran and Vijayakumar 1994). The meteorological data measured by the Central Transdanubian Inspectorate show that relative humidity of the air is throughout the year above $60 \%$, thus favoring the coagulation and settling of the fine particles. Relative humidity of the air is higher in winter than in other seasons, which results in the coagulation of fine particles and their rapid deposition. The material settled during winter is relatively rich in magnetic material, shown by high mass susceptibilities (Fig. 8c). The dust accumulated during winter may be easily re-suspended due to dry surface and windy conditions in spring, resulting in a peak both in dust amount and total susceptibility (Fig. 8, upper and middle diagrams). Later re-suspended magnetite particles contribute less and less to the settled dust, since they are transported away by surface runoff and wind, as shown by the general decreasing trend of the total susceptibility (Fig. 8a).

\section{Conclusions}

Complex magnetic and mineralogical analysis on settled dust samples from 2008 reveals that the mass of the settled dust fails to characterize the degree of anthropogenic pollution. The reason is that summer samples may contain large quantities of natural organic material (like plant fragments, pollen, etc.) which contribute substantially to the mass of the dust. Moreover, the mass of the dust was also increased by the evaporation of algaecide in several August samples. For this reason, the degree of magnetic pollution of anthropogenic origin is better expressed by the total susceptibility than by the mass susceptibility.

The long-term monitoring of the mass and the magnetic susceptibilities of monthly settled dust from 19 sampling sites from North and Central Transdanubia provided sufficient data to average out effects of local and shortterm meteorological conditions on the deposition of the dust containing magnetic particles. We found that irrespective of the degree and source of magnetic pollution the general trend of the rates of dust deposition and the deposition of 
the magnetic grains was similar. At all sampling sites a significant maximum is observed in both the mass susceptibility and the mass of the dust around the third and fourth month of the year. This can be attributed to re-suspension of dust settled in winter. After April, the total susceptibility begins to decrease as the "winter dust" is gradually transported away. The mass of the settled dust, on the other hand, also peaks in June and in August, due to the contribution of algaecide and non-anthropogenic organic material.

Although there is a general and consistent trend at all sampling sites in the monthly variations of the mass of the settled dust and also in total susceptibility, there are considerable differences in the values. Concerning the mass, the highest amounts were detected at monitoring points in Tamási and Mosonmagyaróvár; total susceptibility was far the highest for the Lábatlan and Sopron points. The sampling site in Lábatlan is close to industrial sources, while that in Sopron was located in a main road with heavy vehicle traffic.

Geochemical analysis carried out on the samples from 2008 collected at three key localities (Lábatlan, Mosonmagyaróvár and Sopron) reveal that Cd is the only metal which shows anomalously high concentration everywhere. Its concentration never has a linear relationship with mass susceptibility, suggesting that $\mathrm{Cd}$ does not originate from the sources which emit magnetic particles. The concentrations of the other studied metals mostly show close linear relationships with mass susceptibility. This suggests that the host phases of these elements migrate together with magnetic particles. However, only some of them (such as $\mathrm{Mn}, \mathrm{Zn}, \mathrm{Cr}, \mathrm{Cu}, \mathrm{Pn}$ and V) can be at least partly associated with magnetite in the settled dust.

\section{Acknowledgements}

We thank Péter Márton for carrying out and evaluating the two-frequency susceptibility measurements on selected samples, František Hrouda and Martin Chadima for the opportunity to use the MFK1 instrument for measuring some samples at AGICO and two anonymous referees for revising the manuscript. This work was financially supported by the Hungarian Scientific Research Fund (OTKA K75395 and K76317). We also acknowledge the help of the TÁMOP-4.2.1.B10/2/KONV-2010-0001.

\section{References}

Borbély-Kiss, I., Á.Z. Kiss, E. Koltay, Gy. Szabó, L. Bozó 2004: Saharan dust episodes in Hungarian aerosol: elemental signatures and transport trajectories. - Journal of Aerosol Science, 35/10, pp. 1205-1224.

Chadima, M., J. Kadlec, F. Hrouda, S. Šlechta 2010: Frequency dependence of magnetic susceptibility of weakly magnetic sediments: Implications for magnetic granulometry. - Travaux Géophysiques 39, pp. 11-11.

Dearing, J. 1999: Environmental magnetic susceptibility, Using the Bartington MS2 System. - Chi Publishing, Kenilworth, England. 54 p. 
Farkas, I., T. Weiszburg 2006: Mineralogical investigation of settled and airborne dust collected from Cluj County, Romania. - Földtani Közlöny, 136, pp. 547-572.

Hayakawa, I. 1964: The effects of humidity on the coagulation rate of ammonium chloride aerosols. Journal of the Air Pollution Control Association, 14/9, pp. 339-346.

Jaenicke, R. 1984: Physical aspects of atmospheric aerosol. - In: Gerber, H.E., A. Deepak (Eds): Aerosols and their Climatic Effects. Publishing, Hampton, VA, pp. 7-34.

Ji, Y., Y. Feng, J. Wu, T. Zhu, Z. Bai, C. Duan 2008: Using geoaccumulation index to study source profiles of soil dust in China. - Journal of Environmental Science, 20, pp. 571-578.

Krolak, E. 2000: Heavy metals in falling dust in Eastern Mazowieckie province. - Polish Journal of Environmental Studies, 9, pp. 517-522.

Lázaro FJ., L. Gutiérrez, V. Barrón, M.D. Gelado 2008: The speciation of iron in desert dust collected in Gran Canaria (Canary Islands): Combined chemical, magnetic and optical analysis. Atmospheric Environment, 42, pp. 8987-8996.

Márton, E., F. Hrouda 2010: Estimation of the superparamagnetic contribution to susceptibility of settled dust and PM10 samples using the MFK1-FA Kappabridge, the Bartington MS2 instrument and the method of time-dependence of the saturation IRM. - Travaux Géophysiques, 39, p. 50.

Márton, E., P. Sipos, T. Németh, Z. May 2011: Transport of pollutants around a high building: Integrated magnetic, mineralogical and geochemical study. - In: Conference Proceedings and Exhibitor's Catalogue, 6th Congress of the Balkan Geophysical Society. European Association of Geoscientists and Engineers, B9 pp. 1-6.

Mészáros, E., Á. Molnár, Zs. Horváth 1993: A mikroelemek légköri ülepedése Magyarországon. Agrokémia és Talajtan, 42, pp. 221-228.

Odabasi, M., A. Muezzinoglu, A. Bozlaker 2002: Ambient concentrations and dry deposition fluxes of trace elements in Izmir, Turkey. - Atmospheric Environment, 36, pp. 5841-5851.

Ódor, L., I. Horváth, U. Fügedi 1997: Low-density geochemical mapping in Hungary. - Journal of Geochemical Exploration, 60, pp. 55-66.

Parameswaran, K., G. Vijayakumar 1994: Effect of atmospheric relative humidity on aerosol size distribution. - Indian Journal of Radio and Space Physics, 23, pp. 175-188.

Rood, M.J., D.S. Covert, T.V. Larson 1987: Hygroscopic properties of atmospheric aerosol in Riverside, California. - Tellus, 39b, pp. 383-397.

Rudnick, R., L.S. Gao 2003: The composition of the continental crust. - In: Rudnick, R.L. (Ed.): The Crust. Treatise on geochemistry, 3., Elsevier-Pergamon, Oxford, pp. 1-64.

Sagnotti, L., P. Macrí, R. Egli, M. Mondino 2006: Magnetic properties of atmospheric particulate matter from automatic air sampler stations in Latium (Italy): Toward a definition of magnetic fingerprints for natural and anthropogenic PM10 sources. - Journal of Geophysical Research, $111, \mathrm{~B} 12 \mathrm{~S} 22$

Sagnotti, L., A. Winkler 2012: On the magnetic characterization and quantification of the superparamagnetic fraction of traffic-related urban airborne PM in Rome, Italy. - Atmospheric Environment, 59, pp. 131-140.

Zajzon, N., E. Márton, P. Sipos, F. Kristály, T. Németh, V. Kovács-Kis, T.G. Weiszburg 2013: Integrated mineralogical and magnetic study of magnetic airborne particles from potential pollution sources in industrial-urban environment. - Carpathian Journal of Earth and Environmental Sciences 8/1, pp. 179-186.

Zhao, J., P. Peng, J. Song, S. Ma, G. Sheng, J. Fu 2010: Research on flux of dry atmospheric falling dust and its characterization in a subtropical city, Guangzhou, South China. - Air Quality and Atmospheric Health, 3, pp. 139-147. 